\title{
AOIR
}

Selected Papers of \#AoIR2020:

The $21^{\text {st }}$ Annual Conference of the

Association of Internet Researchers

Virtual Event / 27-31 October 2020

\section{WHO REMAINS OFFLINE AND WHY? THE EVOLUTION OF INDIVIDUAL FACTORS INFLUENCING INTERNET NON-USE FROM 2011 TO 2019 IN A HIGHLY DIGITISED SOCIETY}

\author{
Author \#1 Kiran Kappeler \\ Author \#1 University of Zurich \\ Author \#2 Noemi Festic \\ Author \#2 University of Zurich \\ Author \#2 Michael Latzer \\ Author \#2 University of Zurich
}

\begin{abstract}
Introduction
Obtaining real-time traffic information, applying for jobs, buying things or being an informed citizen increasingly requires internet use. Offline alternatives are often inferior, more expensive or non-existent. Altogether, internet access and use yield many advantages in everyday life in digitised societies and internet non-users are excluded from possibilities for instance in economical, educational and health realms (DiMaggio et al., 2004; van Dijk, 2013). Therefore, factors that predict internet non-use, and their evolution over time are worth examining. This is especially relevant with regard to whether internet non-use is chosen freely (e.g., media resistance; see Syvertsen, 2017) or resides in structural social inequalities (see Robinson et al., 2015). Digital divide research has addressed these structural differences between internet users and nonusers.
\end{abstract}

\section{Theoretical foundations}

Digital divides have been hypothesized to evolve in two different directions over time (van Dijk, 2005, 2013): with increasing internet penetration, socioeconomic differences in access to and use of the internet could either undergo normalisation-where existing differences are expected to fade-or stratification, in which case differences in internet

Suggested Citation (APA): Kappeler, K., Festic, N. \& Latzer, M. (2020, October). Who remains offline and why? The evolution of individual factors influencing internet non-use from 2011 to 2019 in a highly digitized society. Paper presented at AoIR 2020: The 21 th Annual Conference of the Association of Internet Researchers. Virtual Event: AoIR. Retrieved from http://spir.aoir.org. 
adoption and use between socioeconomic groups would remain or be amplified and existing social inequalities would be reproduced instead of alleviated (DiMaggio et al., 2004; Robinson et al., 2015). Thus far, it remains empirically unclear which of the two scenarios has materialized.

\section{Relevance}

In societies where internet adoption is almost universal, the disadvantages of not being online are likely to increase and become even more detrimental to life chances. The growing importance of the internet for additional areas of everyday life renders potential digital divides more severe (van Dijk, 2005). With increasing shares of the population using the internet, those people who cannot profit from its benefits become a potentially disadvantaged minority. Hence, from a public-policy perspective, internet non-use in highly digitised societies should be addressed. For the choice of appropriate public policies to bridge digital divides, empirical assessment of factors influencing internet non-use in highly digitised societies is needed.

\section{Existing empirical research}

Previous studies indicated that differences in socioeconomic background influence patterns of internet use and non-use (Reisdorf \& Groselj, 2017). Whether the development of internet adoption between different societal groups today reflects normalisation or stratification remains unclear since there is only little empirical research on the recent evolution of digital divides. Helsper and Reisdorf (2017), who conducted a comparative study representative of the Swedish and British population on the evolution of digital exclusion from 2005 to 2013, argued that an increasingly vulnerable "digital underclass" is emerging. Still, empirical research on the recent evolution of digital divides in highly connected societies is insufficient. In order to understand how digital divides have evolved and will further evolve in the future, more longitudinal studies are needed. In particular, the choice of appropriate public policies to bridge digital divides requires more longitudinal assessments.

\section{Research questions}

This article contributes to closing this gap by addressing the following research questions: who remains a non-user in a highly connected society and why? How have factors that affect internet non-use evolved since 2011? We investigate whether and how sociodemographic variables explain the probability of individual internet non-use and discusses how such digital divides have evolved in Switzerland from 2011 to 2019. Self-reported reasons for non-use are investigated over time and promotional factors for internet adoption among current non-users are derived.

\section{Method}

This study analysed data from biannually repeated cross-sectional representative surveys of the Swiss population aged 14 years and over from 2011 to $2019\left(N=5{ }^{\prime} 581\right)$. Data was collected through computer-assisted telephone interviews. Multiple binary logistic regressions tested the association of being a non-user with different sociodemographic variables over time. In addition, descriptive statistics were computed to complement the findings with self-reported reasons for non-use and non-users' intention to use the internet. 


\section{Results}

Our results reveal that in Switzerland-a country with one of the highest internet penetrations worldwide- $8 \%$ of the population or about 600,000 people remain internet non-users in 2019. From 2011 to 2019 , higher educational and income levels were consistently negatively associated with the probability of being a non-user. Thus, the lower-educated and economically less affluent were more likely to be non-users. Age had a positive effect on the probability of being a non-user. The effect of age on the likelihood of not using the internet has grown since 2011, resulting in a widening age gap between users and non-users (see Figure 1).

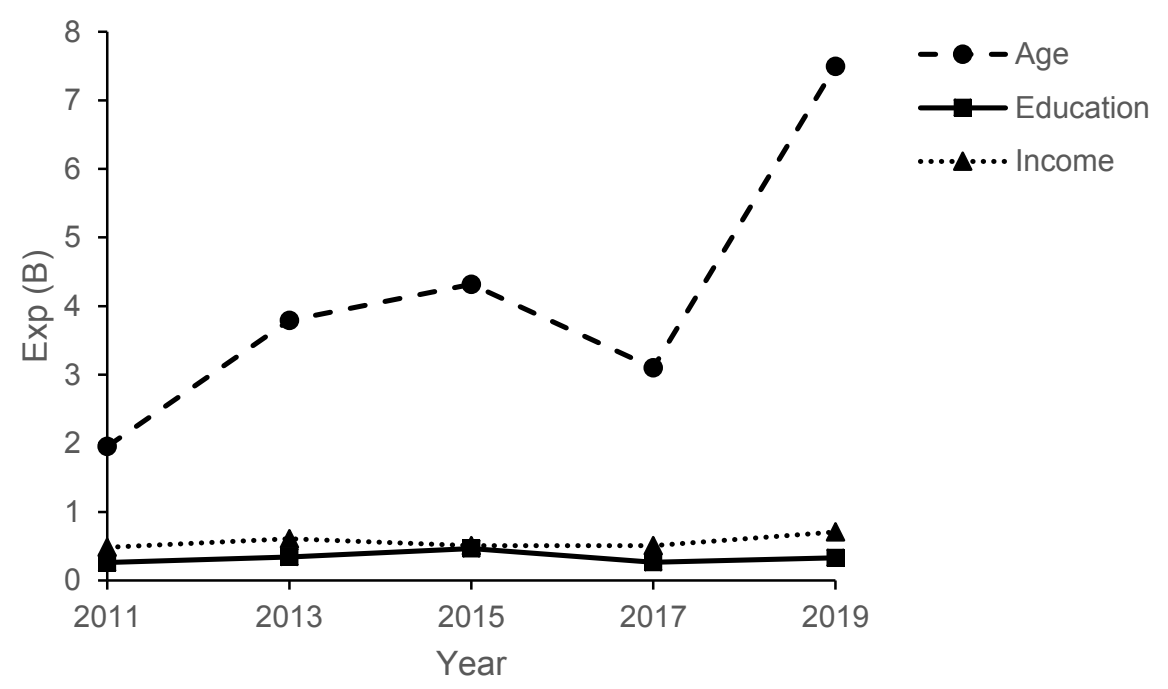

Figure 1. Probability of being an internet non-user.

$\mathrm{N}_{2011}=1,104 ; \mathrm{N}_{2013}=1,114 ; \mathrm{N}_{2015}=1,121 ; \mathrm{N}_{2017}=1,120 ; \mathrm{N}_{2019}=1,120$.

$\operatorname{Exp}(B)$ stands for odds ratios. Only significant effects $(p<.01)$ are depicted.

Gender did not affect individual internet non-use. With regard to gender, normalisation tendencies have therefore been found. In contrast, regarding educational and income level, and age, stratification was observed. Thus, already disadvantaged groups were more likely to be non-users in the examined period in Switzerland.

The most common self-reported reasons for non-use were a lack of perceived usefulness of the internet, followed by feeling too old and having insufficient skills to use it. Interestingly, proxy internet use, i.e., asking someone to do something online, significantly correlated with an increased intention to use the internet. Thus, an increased interest in the internet as well as indirect exposure to it can be identified as key enabling factors for internet use.

\section{Conclusion}

This study's representative, long-term results on the evolution of individual predictors of internet non-use may form the basis for developing targeted, evidence-based policy interventions that promote internet use among specific societal groups. First of all, barriers to internet use related to educational and income level need to be addressed by policies aiming at mitigating the risk of digital exclusion. Furthermore, enhancing the perceived usefulness of the internet among non-users and promoting internet skills are promising starting points for policy interventions. Finally, our results highlight the 
importance of indirect exposure to the internet for an increased willingness to use it. Increasing the possibilities for proxy internet use may thus be another policy focus.

\section{References}

DiMaggio, P., Hargittai, E., Celeste, C., \& Shafer, S. (2004). From Unequal Access to Differentiated Use. In K. Neckerman (Eds.), Social Inequality (p. 355-400). Russell Sage Foundation.

Helsper, E. J., \& Reisdorf, B. C. (2017). The Emergence of a "Digital Underclass" in Great Britain and Sweden: Changing Reasons for Digital Exclusion. New Media \& Society, 19(8), 1253-1270. https://doi.org/10.1177/1461444816634676

Reisdorf, B., \& Groselj, D. (2017). Internet (Non-)Use Types and Motivational Access: Implications for Digital Inequalities Research. New Media \& Society, 19(8), 1157-1176. https://doi.org/10.1177/1461444815621539

Robinson, L., Cotten, S. R., Ono, H., Quan-Haase, A., Mesch, G., Chen, W., Schulz, J., Hale, T. M., \& Stern, M. J. (2015). Digital Inequalities and Why They Matter.

Information, Communication \& Society, 18(5), 569-582.

https://doi.org/10.1080/1369118X.2015.1012532

Syvertsen, T. (2017). Media Resistance_Protest, Dislike, Abstention. Palgrave Macmillan.

van Dijk, J. A. G. M. (2005). The Deepening Divide: Inequality in the Information Society. SAGE Publications.

van Dijk, J. A. G. M. (2013). A Theory of the Digital Divide. In M. Ragnedda \& G. W. Muschert (Eds.), The Digital Divide: The Internet and Social Inequality in International Perspective (p. 29-51). Routledge. 